\title{
Case Report \\ Eyelid Edema: A Rare Cause of a Common Sign
}

\author{
Andreia Soares, ${ }^{1}$ Cristina Almeida, ${ }^{1}$ Cristina Freitas, ${ }^{1}$ \\ Marco Sales-Sanz, ${ }^{2}$ and Sara Ribeiro, ${ }^{1,3}$ \\ ${ }^{1}$ Hospital de Braga, School of Medicine, University of Minho, Braga, Portugal \\ ${ }^{2}$ Ophthalmology Department, Hospital Universitario Ramón y Cajal, Madrid, Spain \\ ${ }^{3}$ Ophthalmology Department, Hospital Lusíadas, Porto, Portugal \\ Correspondence should be addressed to Andreia Soares; andreiafilipa.brsoares@gmail.com
}

Received 24 April 2017; Accepted 2 July 2017; Published 7 August 2017

Academic Editor: Alexander A. Bialasiewicz

Copyright (C) 2017 Andreia Soares et al. This is an open access article distributed under the Creative Commons Attribution License, which permits unrestricted use, distribution, and reproduction in any medium, provided the original work is properly cited.

\begin{abstract}
We report a 48-year-old female patient who presented to the emergency room with right eyelid edema, with 3 days of evolution. She had suffered minor trauma to this eye one week before. She reported episodes of right eyelid swelling of spontaneous resolution since the occurrence of a traumatic brain injury 5 years ago. Ophthalmological examination showed a soft and painless eyelid edema of the right eye. Brain computed tomography showed an area of bone discontinuity of the orbital roof with brain herniation and a CSF leak into the eyelid (blepharocele). Magnetic resonance confirmed the result of TC and revealed an area of frontal encephalomalacia. Ibuprofen $(800 \mathrm{mg} /$ day) was prescribed, with complete resolution within 20 days. She was evaluated by Neurosurgery with no indication of surgery due to the resolution of the edema and absence of symptoms. Blepharocele is a rare entity that should be considered in the differential diagnosis of unilateral eyelid edema. It can be secondary to an orbital fracture or congenital lesion.
\end{abstract}

\section{Introduction}

A cerebrospinal fluid fistula is defined as the communication between the subarachnoid space and the external environment [1]. These fistulas complicate $2 \%$ of all head traumas and occur in $12-30 \%$ of all basilar skull fractures. Otorrhea or rhinorrhea are more common presentations, but, in rare situations, CSF can collect in the orbit (orbitocele) or in the upper eyelid (blepharocele) [2]. Most of the few cases described in the last 55 years have occurred in children, probably due to the immaturity of a child's frontal sinus [3-8]. Ommaya et al. [9] proposed a classification of cerebrospinal fluid fistulas, dividing them into traumatic (iatrogenic or accidental) or nontraumatic origin (idiopathic or secondary).

Blepharocele is a rare entity. If the content is only CSF, the eyelid swelling may be transilluminant. The onset of the fistulas may be seen later in the form of eyelid swelling precipitated by a microtrauma, independently of their etiology (congenital or traumatic) $[1,3,10]$.

We report here the case of a female adult patient with blepharocele precipitated by a microtrauma.

\section{Case Report}

A 48-year-old female patient presented in the emergency room with eyelid edema in the right eye, with 3 days of evolution (Figure 1). She had suffered a minor trauma to this eye one week before, caused by the hand of her 2-year-old son. She reported previous episodes of swelling in the same eye, with spontaneous improvement, since the occurrence of a major head trauma five years ago. At that time, she had not been evaluated by a medical professional and had not been submitted to any neuroradiological exam.

The ophthalmological examination showed a soft and painless eyelid edema of the right eye, without signs of inflammation or cutaneous lesions. Best corrected visual acuity was $20 / 20$ in both eyes. Pupils were equal and reactive to light. Ocular motility, exophthalmometry, anterior biomicroscopy, intraocular pressure, and fundoscopy were normal. Brain tomography scans showed an area of bone discontinuity of the orbital roof with brain herniation and a CSF leak into the eyelid (Figure 2). Magnetic resonance of the orbits confirmed the result of computed tomography $(\mathrm{CT})$ and revealed an area 
TABLE 1: Literature review of blepharocele case reports.

\begin{tabular}{|c|c|c|c|c|c|}
\hline & Author, year & Gender/age & Mechanism & Clinical manifestation & Treatment \\
\hline (1) & Bagolini, 1957 & $\mathrm{NS} / 9 \mathrm{~m}$ & Car accident & $\begin{array}{c}\text { Tearing (“Oculorrhea”) } \\
\text { UE Hematoma } \\
\text { Anisocoria } \\
\end{array}$ & Surgical \\
\hline (2) & Garza-Mercado, 1982 & $\mathrm{M} / 20 \mathrm{y}$ & Assault & $\begin{array}{c}\text { Tearing (“Oculorrhea”) } \\
\text { Eyelid edema } \\
\text { Ecchymosis } \\
\text { Limited EOM }\end{array}$ & Surgical \\
\hline (3) & Till, 1987 & $\mathrm{M} / 14 \mathrm{~m}$ & $\begin{array}{l}\text { Stabbing } \\
\text { wound }\end{array}$ & $\begin{array}{c}\text { Tearing ("Oculorrhea”) } \\
\text { Eyelid edema }\end{array}$ & Surgical \\
\hline (4) & Bhatoe, 2002 & $\mathrm{M} / 25 \mathrm{y}$ & Traffic collision & $\begin{array}{c}\text { Eyelid swelling } \\
\text { Periorbital ecchymosis }\end{array}$ & $\begin{array}{l}\text { TC surgery } \\
\text { Dural repair }\end{array}$ \\
\hline (5) & Arslantas, 2003 & $\mathrm{NS} / 3 \mathrm{y}$ & Fall & Orbitocele & $\begin{array}{l}\text { TC surgery } \\
\text { Dural repair }\end{array}$ \\
\hline (6) & Chandra, 2013 & $\mathrm{~F} / 4 \mathrm{y}$ & $\begin{array}{c}\text { Blunt head } \\
\text { injury }\end{array}$ & UE swelling & $\begin{array}{l}\text { TC surgery } \\
\text { Dural repair }\end{array}$ \\
\hline (7) & Borumandi, 2013 & $\mathrm{~F} / 49 \mathrm{y}$ & Fall & $\begin{array}{c}\text { Eyelid swelling } \\
\text { Ecchymosis }\end{array}$ & Conservative \\
\hline (8) & Govindaraju, 2013 & $\mathrm{M} / 43 \mathrm{y}$ & Head injury & Eyelid swelling & $\begin{array}{l}\text { TC surgery } \\
\text { Dural repair }\end{array}$ \\
\hline (9) & Germano, 2015 & $\mathrm{~F} / 51 \mathrm{y}$ & Congenital lesion & Eyelid swelling & $\begin{array}{c}\text { TC surgery } \\
\text { Dural repair }\end{array}$ \\
\hline
\end{tabular}

y: years; m: months; NS: not stated; EOM: extraocular movements; UE: upper eyelid.

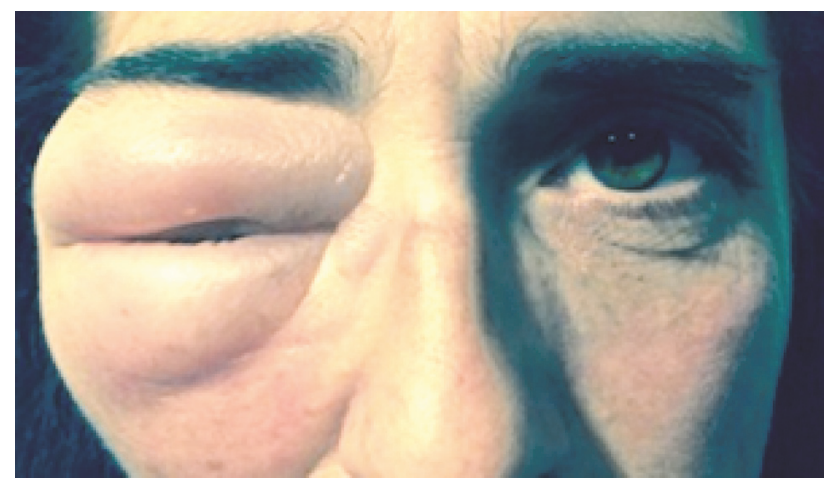

FIGURE 1: Clinical appearance of the patient with right eyelid edema.

of frontal encephalomalacia probably related to the previous trauma (Figure 3). She was treated with a nonsteroidal antiinflammatory drug (ibuprofen, $800 \mathrm{mg} /$ day) for 2 weeks, with total improvement of the edema. Neurosurgical evaluation was requested and there was no indication for surgery due to resolution of the edema and absence of symptoms. Neurological examination was normal, with no focal deficits.

\section{Discussion}

Blepharocele is a rare ophthalmological entity. The main cause is head trauma, but the condition can be associated with congenital lesions. We found 9 cases described in the literature (Table 1), 8 with traumatic etiology and one with congenital etiology $[1,3-5,7,8,10-12]$. The etiology of the blepharocele of our patient is undetermined. It could be associated with the head trauma she had 5 years ago, as suspected by the area of encephalomalacia, probably related to a cerebral contusion. However, we have no records of a clinical evaluation or any neuroradiological exam of this event or of previous brain and orbit imaging exams.

CSF leaks have been reported to manifest months or even years after the initial trauma. The onset of the fistulas may be seen in the form of eyelid swelling late after the trauma. The literature contains few reports of CSF leakage whose onset was delayed by more than 30 years [12]. Several precipitating factors such as coughing and undetected minor traumas could be responsible for this unusually late manifestation of the fistula. In our case, it could be associated with the recent minor trauma caused by the hand of her son. The temporary seal provided by a clot, inflammatory granulation, contusional cerebral adhesions, or mucocele may be broken down, resulting in late accumulation [12].

On the other hand, this late manifestation may be associated with a congenital lesion. Ommaya et al. [9] reported a pathophysiological explanation for nontraumatic blepharocele. Their theory, called focal atrophy, is based on a reduction of volume of cribriform structures and the sella turcica by an ischemic mechanism. The space created would be filled with CSF, exerting an erosive force in the skull. Bone defects in the skull base allow the creation of small meningeal hernias which lead to the formation of cerebrospinal fluid fistula [1].

Most traumatic CSF leaks resolve spontaneously without treatment, the majority within the first $24-48$ hours, as a result of blood products and/or inflammatory adhesions at the site of the dural breach and associated skull fracture. Herniation of the brain tissue into the traumatic defect may 


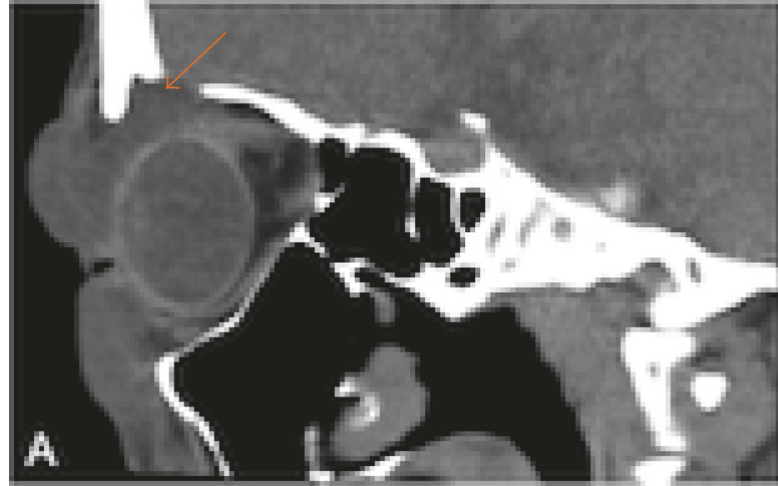

(a)

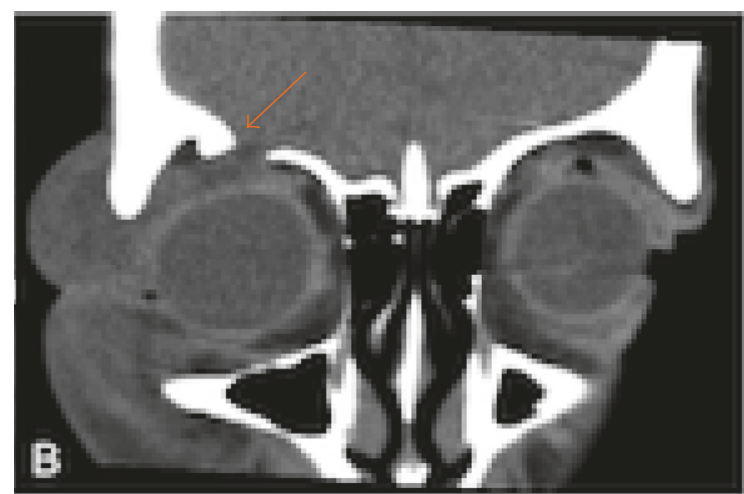

(b)

FIGURE 2: Orbital CT scans ((a) sagittal scan, (b) coronal scan) revealed an area of bone discontinuity in the right orbital roof with adjacent cephalocele (arrow).

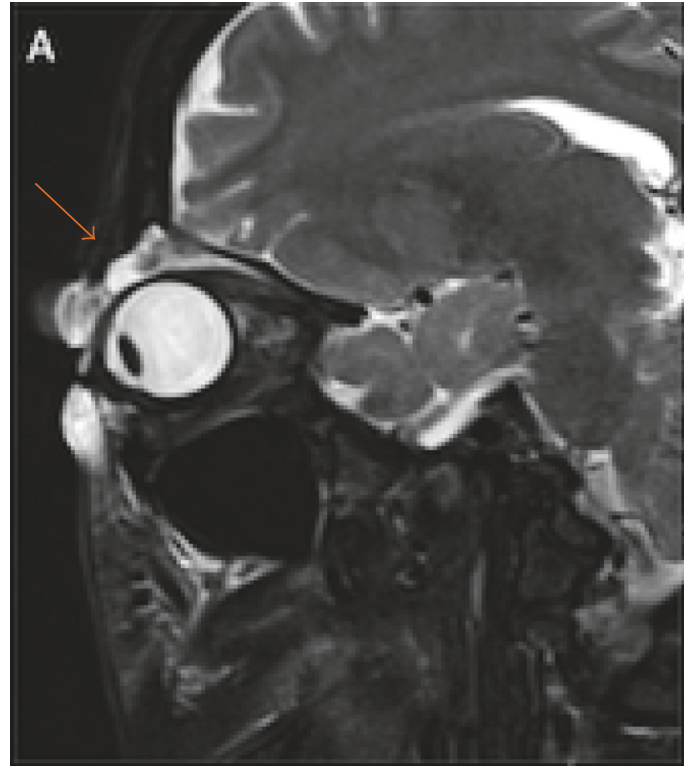

(a)

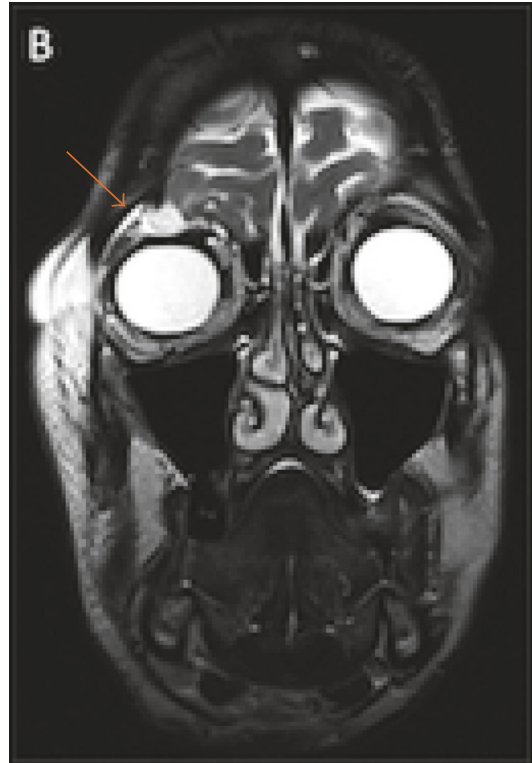

(b)

FIGURE 3: Orbital MR ((a) sagittal scan, (b) coronal scan) showed an area of bone discontinuity in the anterior right orbital roof with adjacent cephalocele (extraconic) and a frontobasal area of encephalomalacia related to trauma.

also play a role in the cessation of the leak. Aspiration of posttraumatic eyelid swelling may result in disastrous consequences and should not be done. Patients with leaks that persist for more than 24 hours may be at increased risk for meningitis, and surgical intervention is required. The cosmetic and functional results of surgery have been reported to be excellent $[3,4,10]$.

Blepharocele is a rare condition but it is important to consider this diagnosis in patients with eyelid swelling without resolution after minor or major traumas.

\section{Conflicts of Interest}

The authors declare that there are no conflicts of interest regarding the publication of this paper.

\section{References}

[1] R. A. S. Germano, M. V. Silva, F. A. S. Germano et al., "Eyelid liquoric fistula secondary to orbital meningocele," Revista Brasileira de Oftalmologia, vol. 74, no. 1, pp. 46-48, 2015.

[2] M. Pease, Y. Marquez, A. Tuchman, A. Markarian, and G. Zada, "Diagnosis and Surgical Management of Traumatic Cerebrospinal Fluid Oculorrhea: Case Report and Systematic Review of the Literature," Journal of Neurological Surgery Reports, vol. 74, no. 01, pp. 057-066, 2013.

[3] N. Chandra, B. K. Ojha, V. Chandwani, C. Srivastava, S. K. Singh, and A. Chandra, "A rare case of posttraumatic eyelid swelling: Cerebrospinal fluid blepharocele," Journal of Neurosurgery: Pediatrics, vol. 11, no. 3, pp. 242-244, 2013.

[4] H. S. Bhatoe, "Blepharocele after head injury," Skull Base, vol. 12, no. 2 , pp. 73-76, 2002. 
[5] V. Govindaraju and R. Bharathi, "Post-traumatic blepharocele in an adult," Sultan Qaboos University Medical Journal, vol. 13, no. 3, pp. 479-481, 2013.

[6] A. Aggarwal, A. K. Gupta, and A. K. Aggarwal, "Acute posttraumatic encephalocele in a child: CT and MRI features," BJR-Case Reports, vol. 2, no. 4, p. 20150170, 2016.

[7] B. Bagolini, "Leakage of Spinal Fluid into Upper Lid Following Trauma," A.M.A. Archives of Ophthalmology, vol. 57, no. 3, pp. 454-456, 1957.

[8] R. Garza-Mercado, J. Aragon-Lomas, J. Martinez-Garza, and L. Leal-Hernandez, "Cerebrospinal fluid blepharocele: An unusual complication of head injuries," Neurosurgery, vol. 11, no. 4, pp. 525-526, 1982.

[9] A. K. Ommaya, G. Di Chiro, M. Baldwin, and J. B. Pennybacker, "Non-traumatic cerebrospinal fluid rhinorrhoea," Journal of Neurology Neurosurgery and Psychiatry, vol. 31, no. 3, pp. 214225,1968

[10] H. S. Bhatoe, "Blepharocele following head injury in a child," The Indian Journal of Neurotrauma, vol. 2, no. 1, pp. 51-53, 2005.

[11] G. J. Liem, C. dos Reis Lisboa-Neto, F. Mendes Paschoal Junior et al., "Persistent post-traumatic orbital cerebrospinal Fluid Fistula with multiple episodes of meningitis: Systematic Case Review and Case Report," International Archives of Medicine, vol. 9, no. 179, pp. 1-7, 2016.

[12] A. Arslantas, M. Vural, M. Atasoy, A. Ozsandik, S. Topbaş, and E. Tel, "Posttraumatic cerebrospinal fluid accumulation within the eyelid: a case report and review of the literature," Child's Nervous System, vol. 19, pp. 54-56, 2003. 


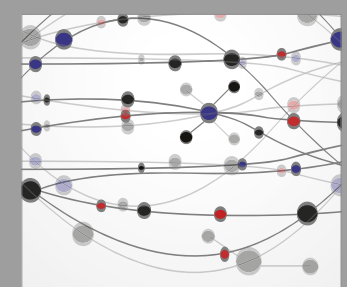

The Scientific World Journal
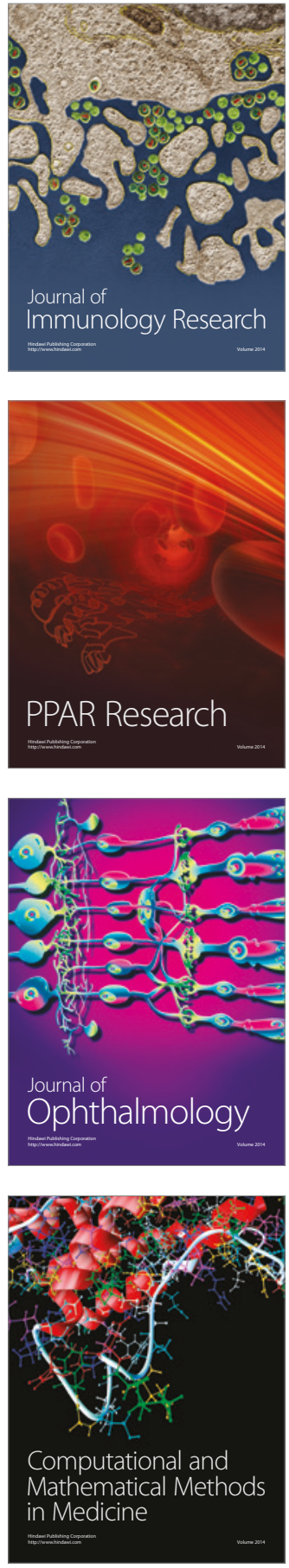

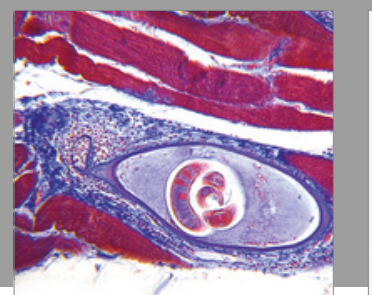

Gastroenterology Research and Practice
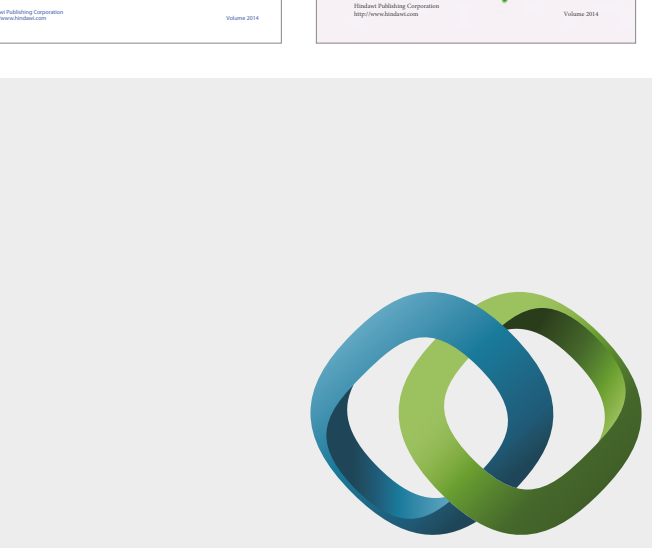

\section{Hindawi}

Submit your manuscripts at

https://www.hindawi.com
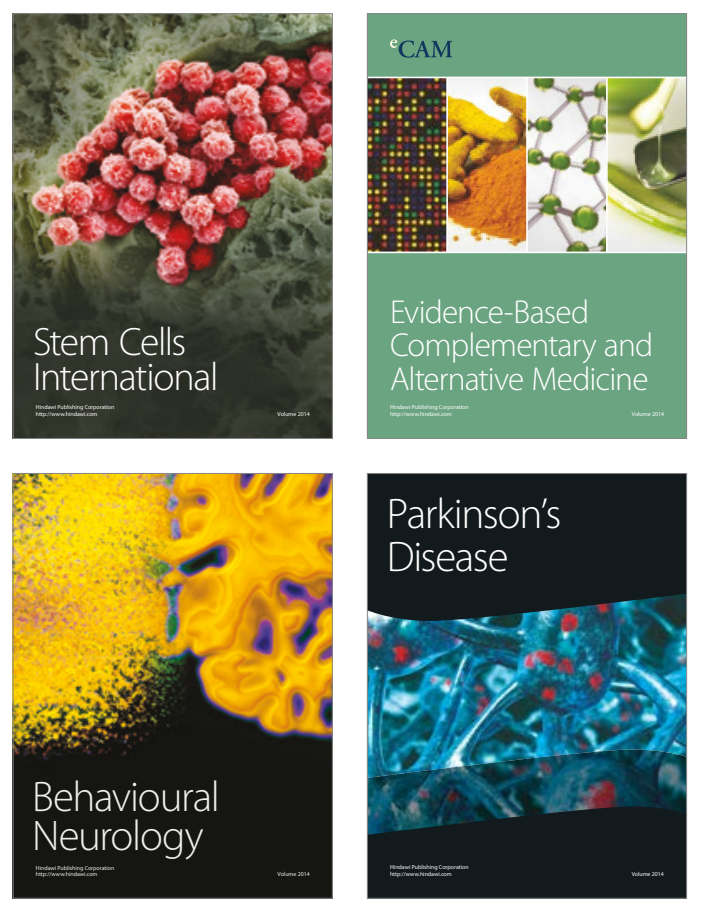
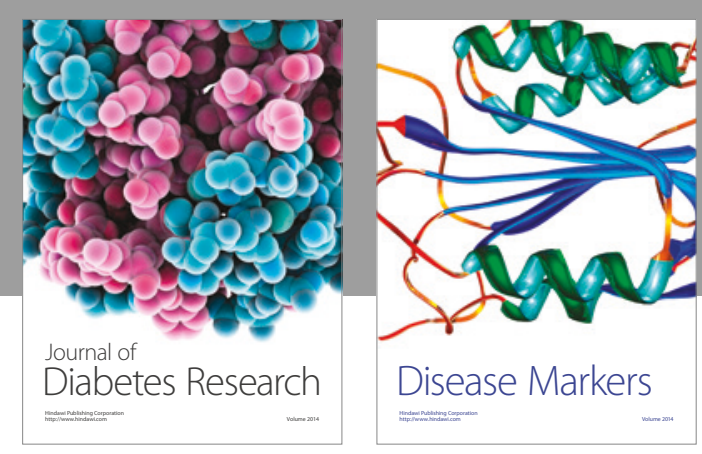

Disease Markers
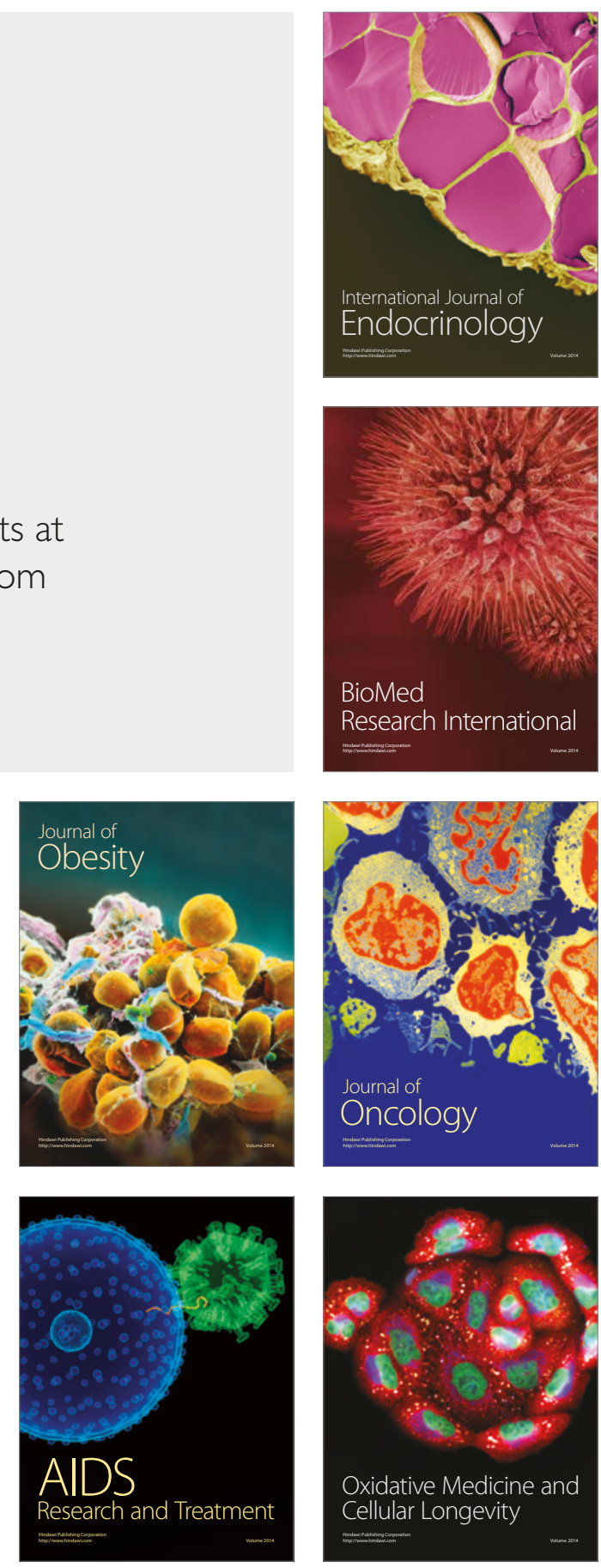